\title{
Fatigue Lifetime of ADI from Ultimate Tensile Strength to Permanent Fatigue Limit
}

\author{
J. Zapletal, ${ }^{1, a}$ S. Věchet, ${ }^{1, b}$ J. Kohout, ${ }^{2, c}$ and K. Obrtlík ${ }^{3, d}$ \\ ${ }^{1}$ Brno University of Technology, Brno, Czech Republic \\ ${ }^{2}$ University of Defence, Brno, Czech Republic \\ ${ }^{3}$ Institute of Physics of Materials, Academy of Sciences of the Czech Republic, Brno, Czech \\ Republic
}

a pepa.sanguis@centrum.cz, ${ }^{\mathrm{b}}$ vechet@fme.vutbr.cz, ${ }^{\mathrm{c}}$ jan.kohout@unob.cz, ${ }^{\mathrm{d}}$ obrtlik@ipm.cz

$S-N$ curve of austempered ductile iron was obtained in the range of lifetime including low cycle fatigue domain and high cycle fatigue domain up to $10^{8}$ cycles. Ultimate tensile strength is used as a limiting value of the curve. Symmetric push-pull fatigue and tensile tests were performed at room temperature on isothermally treated nodular cast iron alloyed with copper and nickel having positive impact on mechanical, technological and fatigue properties of austempered ductile iron. Suitable functions for the fit of experimentally determined points were tested and their parameters were calculated. The best results were obtained using the Palmgren function and the function introduced by Kohout and Vechet. Since the loading frequency in high-cycle region is two orders higher than in low-cycle region, the effect of loading cycle frequency on fatigue behavior of the studied material is also studied. A possibility of discontinuity of experimental data between low-cycle and high-cycle regions is discussed.

Keywords: austempered ductile iron, fatigue behavior, $S-N$ curve, fatigue limit, low-cycle fatigue tests, high-cycle fatigue tests, regression.

Introduction. Nodular cast iron and its isothermally heat treated variant, austempered ductile iron (ADI), are structural materials applied in many branches of mechanical and civil engineering and transportation. Comparing with other sorts of cast iron, its advantage consists in favorable shape of graphite, which enables full exploitation of mechanical properties of the metal matrix. Recently ADI has been used for the production of crankshafts, engine blocks, rotors of electric generators, gas compressor casings, large gears, pressing dies, wheels of colliery cars, etc. [1].

Experimental. The test bars for static mechanical tests in tension as well as for fatigue tests were made of keel blocks of alloyed nodular cast iron. Its chemical composition determined using quantometer is presented in Table 1. Isothermal heat treatment resulting in a bainitic structure was performed in electric pot furnaces containing salt bathes. Austenization was realized in the salt bath at a temperature of $900^{\circ} \mathrm{C}$ for $1 \mathrm{~h}$. Isothermal decomposition was performed in the AS 140 salt bath at $400^{\circ} \mathrm{C}$ during $50 \mathrm{~min}$ with aftercooling in water. The matrix of the material studied consisted of upper bainite and stabilized retained austenite, whose content was determined using quantitative phase $\mathrm{X}$-ray analysis to be $39 \mathrm{vol} . \%$. For the determination of the basic mechanical properties at static tensile loading, cylindrical test bars $6 \mathrm{~mm}$ in diameter were tested. The elongation of the test bars was measured by an extensometer with a gauge length of $30 \mathrm{~mm}$. Tests were performed using a Mod. TiraTest 2300 PC-controlled testing device at a stress rate of $30 \mathrm{MPa} / \mathrm{s}$. The basic stress and strain characteristics are summarized in Table 2.

For the assessment of low-cycle parameters the threaded bars of diameter $8 \mathrm{~mm}$ and a gauge length of $12 \mathrm{~mm}$ were used. They were loaded using MTS 810 electro-hydraulic PC-controlled test system in the regime of a controlled loading force with a symmetric sinusoidal push-pull course at an average stress rate of $4000 \mathrm{MPa} / \mathrm{s}$. Deformation was measured using an axial extensometer with a gauge length of $12 \mathrm{~mm}$. Also, high-cycle

(C) J. ZAPLETAL, S. VĚCHET, J. KOHOUT, K. OBRTLIK, 2008 
fatigue tests were performed using 7-mm-diameter bars with threaded heads. A Mod. Amsler HFP 1478 high-frequency pulsator was used to load the bars with a symmetric push-pull loading cycle with a frequency of about $200 \mathrm{~Hz}$. All fatigue tests as well as static tensile tests were carried out at room temperature.

$\mathrm{T}$ a b 1 e 1

Chemical Composition of Nodular Cast Iron under Study

\begin{tabular}{|c|c|c|c|c|c|c|c|c|}
\hline Element & $\mathrm{C}$ & $\mathrm{Mn}$ & $\mathrm{Si}$ & $\mathrm{P}$ & $\mathrm{S}$ & $\mathrm{Ni}$ & $\mathrm{Cu}$ & $\mathrm{Mg}$ \\
\hline wt. $\%$ & 3.80 & 0.37 & 2.22 & 0.024 & 0.002 & 0.49 & 0.31 & 0.057 \\
\hline
\end{tabular}

$\mathrm{T}$ a b 1 e 2

Static Mechanical Characteristics of ADI in Tension

\begin{tabular}{|c|c|c|c|c|}
\hline Material & $R_{p 0.2}, \mathrm{MPa}$ & $R_{m}, \mathrm{MPa}$ & $A, \%$ & $Z, \%$ \\
\hline ADI $400^{\circ} \mathrm{C} / 50 \mathrm{~min}$ & 636 & 976 & 11.4 & 9.7 \\
\hline
\end{tabular}

Data Processing of Experimental Results. The experimentally obtained dependence of the stress amplitude $\sigma(N)$ on the number of cycles to fracture $N$ in the range from 0.5 to $10^{8}$ cycles was fitted using two different regression functions: the Palmgren function [2]

$$
\sigma(N)=a(N+B)^{b}+\sigma_{\infty}
$$

and the Kohout-Věchet function [3]

$$
\sigma(N)=\sigma_{\infty}\left(\frac{N+B}{N+C}\right)^{b}
$$

where $a, b, B, C$, and $\sigma_{\infty}$ are the regression parameters. The meaning of all parameters is unequivocal and with a close relation to geometrical shape of the curve only in the case of the Kohout-Věchet function: $\sigma_{\infty}$ means the permanent fatigue limit for an infinite number of cycles to fracture (giga-cycle fatigue is not considered here), $B$ and $C$ represent the positions of curve bends, and $b$ is the curve slope at the point of inflexion when the curve is plotted in the $\log -\log$ scale. In the case of the Palmgren function, the relation between parameter $b$ and the slope is not so direct and the parameter $a$ has a rather complicated meaning.

Test Results and Discussion. The experimental dependence of the stress amplitude on the number of cycles to fracture was fitted using both Eq. (1) and (2), see Figs. 1, 2 , and 3, where both fits are compared. The values of regression parameters together with the calculated fatigue limit for $10^{7}$ cycles to fracture and the sum of squares of deviations between measured and fitted values $S$ are presented in Table 3 .

The difference in fits using different regression functions is evident at first sight: Eq. (2) leads to a better fit than Eq. (1) does. This first impression is supported by the values of the sums of squares: for Eq. (2) only $72 \%$ of the value corresponding to Eq. (1) is obtained. Moreover, two regions of the numbers of cycles to fracture are better described using Eq. (1): the low-cycle region from $10^{2}$ to $10^{5}$ cycles and the high-cycle region above $10^{7}$ cycles. It means that Eq. (2) has a better limiting behavior than that of Eq. (1). Quantitatively it can be best expressed by the standard deviations of the parameter $\sigma_{\infty}$ representing the limiting behavior of both equations: it was calculated to be $\sigma_{\infty}=(226.9$ $\pm 30.3) \mathrm{MPa}$ for Eq. (1) and $\sigma_{\infty}=(310.1 \pm 8.8) \mathrm{MPa}$ for Eq. (2). 


\begin{tabular}{|c|c|c|c|c|c|c|}
\hline T a b l e 3 & Results of Regression Calculations \\
\hline Parameter & $\sigma_{\infty}, \mathrm{MPa}$ & $b$ & $B$ & $a, \mathrm{MPa}$ or $C$ & $\sigma_{C}, \mathrm{MPa}$ & $S$ \\
\hline Eq. (1) & 226.9 & -0.1882 & 65.02 & 1627.62 & 305.2 & 20,543 \\
\hline Eq. (2) & 310.1 & -0.1086 & 33.11 & 1212,180 & 314.0 & 14,738 \\
\hline
\end{tabular}

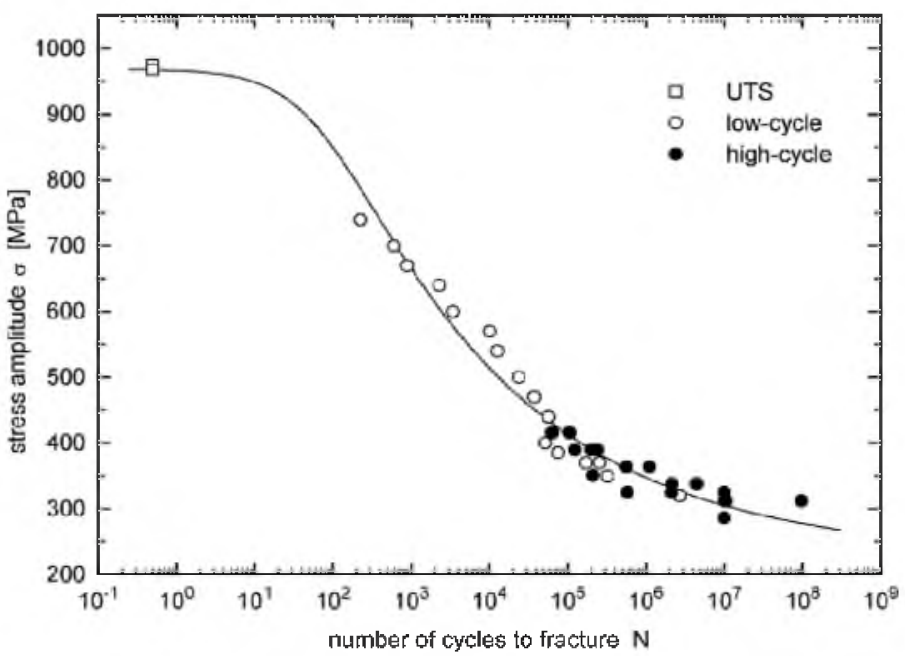

Fig. 1. $S-N$ curve of the studied ADI, fitted by the Palmgren function (1).

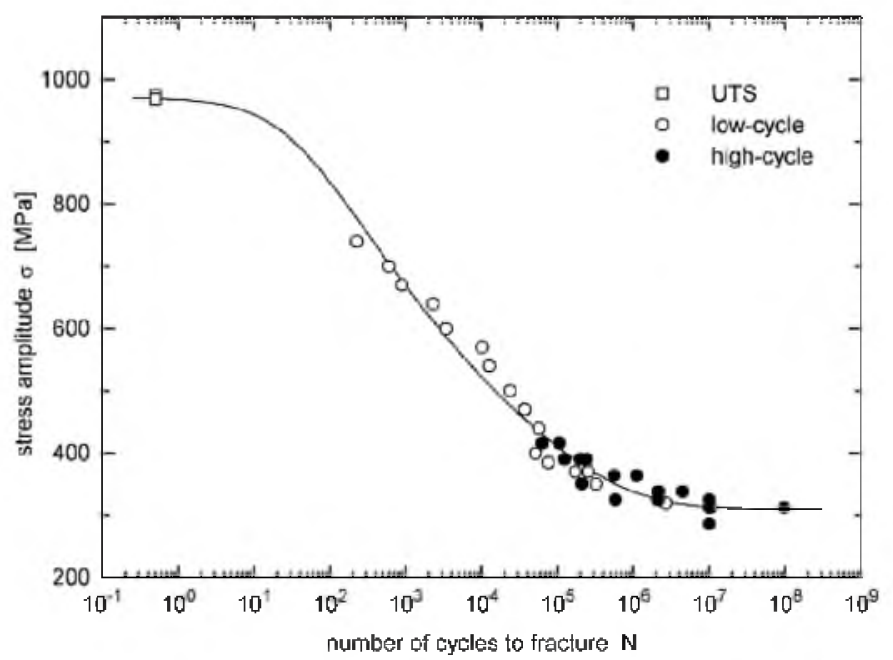

Fig. 2. $S-N$ curve of the studied ADI, fitted by the Kohout-Vèchet function (2).

Discontinuities between a low-cycle and high-cycle regions are often reported not only as results of experimental tests $[4,5]$ but also as conclusions of theoretical considerations [6, 7]. However, in Figs. 1, 2, and 3 both the 1ow- and high-cycle results are plotted commonly and it can be seen here that no discontinuity exists between them. Even in two orders of the number of cycles to fracture the low- and high-cycle experimental points overlap and their link-up is ideal, without any sign of break or shift. It can serve as an indirect evidence that both types of tests were performed correctly and responsibly. 


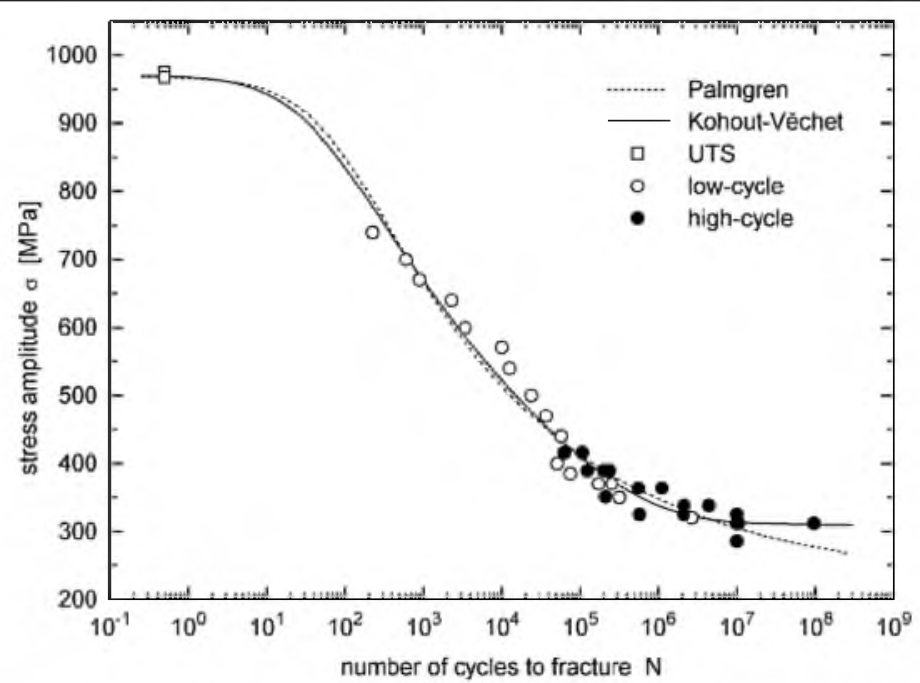

Fig. 3. Comparison of the fits by the Palmgren function (1) and by the Kohout-Věchet function (2).

Generally, it is very hard to tell if the above-mentioned discontinuities are only experimental artefacts or if they can have a principal cause. It is most probable that at least in some cases the discontinuities can be attributable to changed experimental conditions, inaccurate measurements or incorrect conversion between low-cycle and high-cycle data.

\section{Conclusions}

1. No discontinuity was found between the low- and high-cycle regions in experimental results of ADI studied, even when the loading frequencies differ by two orders of magnitude ( 1 to $200 \mathrm{~Hz}$ ).

2. The experimental fatigue test results in the whole range of the number of cycles to fracture can be fitted using the Palmgren function and the Kohout-Vêchet function. The latter provides a better fit in a low-cycle as well as high-cycle regions.

3. A relatively high value of the fatigue limit $\sigma_{C}=314 \mathrm{MPa}$ means that the optimum regime of heat treatment was applied.

Acknowledgements. The financial supports by the Ministry of Defense of the Czech Republic within the Research Project No. MO0FVT0000404 and by the Grant Agency of the Czech Republic within the Grant Project No. 106/03/1265 are gratefully acknowledged.

1. E. Dorazil, High Strength Austempered Ductile Cast Iron, Horwood, London (1991).

2. W. Weibull, Fatigue Testing and Analysis of Results, Pergamon Press, London etc. (1962).

3. J. Kohout and S. Vèchet, Int. J. Fatigue, 23, 175 (2001).

4. D. S. Matsumoto and S. K. Gifford, J Mater. Sci., 20, 4610 (1985).

5. R. Boukhili and R. Gauvin, J. Mater. Sci. Lett., 9, 449 (1989).

6. J. Pokluda, F. Kroupa, and L. ObdrŽálek, Mechanical Properties and Structure of Solids [in Czech], PC-DIR, Brno (1994).

7. A. Puškár and M. Hazlinger, Failure and Fractures of Details [in Slovak], University of Žilina, Žilina (2000). 